\title{
Laptop Use During Class: A Review Of Canadian Universities
}

Romulus Cismaru, University of Regina, Canada

Magdalena Cismaru, University of Regina, Canada

\begin{abstract}
Laptop use in class is a characteristic of universities that is changing rapidly. Although much of the attention and research regarding this issue has focused on the debate of whether to impose mandatory laptop programs, the reality of wireless campuses allows students to use their laptops in class for class related and non-class related activities. Therefore, a new debate has arisen concerning whether students should be allowed to use their laptops in class at all. The purpose of this article is to provide an overview of Canadian universities in terms of their conditions, requirements, and policies regarding laptop use in class.
\end{abstract}

Keywords: Laptop Use; College Students; Wireless; Canada

\section{INTRODUCTION}

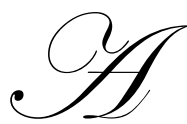

-11 but a very small number of Canadian universities have wireless networks on their campuses. Wireless access to the Web allows students to make use of the Internet for in-class activities, such as accessing documents or taking online quizzes. Moreover, wireless access can contribute to a feeling of active engagement in learning among students and improve their ability to understand materials (Aziz, Khan, \& Singh, 2010). Because of the potential benefits of laptop usage in class, universities such as Acadia University and Quest University require all students to own a laptop. However, wireless access to the Web allows students to engage in other Web-related activities during class, such as instant messaging, online shopping, paying bills online, watching videos, playing games, and browsing social network sites (Hill \& Epps, 2010; Tan \& Morries, 2005; University of Guelph Learning Services, 2010; Young, 2006). These non-class related activities have the potential to decrease student performance (Bowman, Levine, Waite, \& Gendron, 2010; Fried, 2008; Kirschner \& Karpinski, 2010; Kraushaar \& Novak, 2010) and disrupt classes (Fried, 2008). Indeed, evidence shows that laptop use in class negatively affects students' attention, performance, and understanding of class material (Fried, 2008; Lovett, 2009; Jarmon, 2008; Rubinstein, Meyer, \& Evans, 2001). It has also been found to reduce class dynamics and interaction, increase frustration among professors, and distract other students with the tapping sound of numerous keyboards or the displaying of inappropriate visual content (Morton, 2009). Consequently, an increasing number of faculty members are banning laptops from their classrooms (Fried, 2008). Most Canadian universities do not seem to have any stated guidelines or policies regarding laptop use during class time. Some schools, including McGill University and the University of Windsor, have guidelines that leave the decision to ban laptops from classes to the instructor, whereas other schools, such as the University of Waterloo, consider the banning of laptops from classrooms to be unacceptable due to the negative impact on special needs students but suggest creating laptop-free zones to help students maintain focus (Morton, 2009).

\section{PURPOSE AND OUTLINE}

Given the debate surrounding laptop use during university classes and the lack of consistency in terms of guidelines and policies on this issue across Canada, we conducted research aimed toward the following objectives: reviewing existing evidence for current trends at Canadian universities regarding wireless networks and student use of laptops in class; presenting the advantages and disadvantages of student laptop use during classes and ways to address this issue; and reviewing the current guidelines and policies in Canadian universities regarding laptop use in class. 
This study involved extensive online research of materials and articles regarding laptop use in class by university students. Most of the information was obtained from the universities' websites and from academic articles found in databases such as Education: A SAGE Full-Text Collection, Expanded Academic ASAP, JSTOR, Academic Search Complete, Proquest Education Journals, and Psychology: A SAGE Full-Text Collection. The focus was on Canadian universities.

\section{LITERATURE REVIEW}

Most of the universities in Canada have wireless networks across campuses, meaning that individuals have the ability to access computing resources regardless of where they are physically located on campus without having to plug their laptops into a network (Bagley, Bristow, Rhodes, \&Rubin, 2003). Reasons for why a wireless network is desirable in any university campus include mobility and convenience, ease and convenience of access for students, competition, classroom flexibility, and costs and time to implement (Bagley et al., 2003). Evidence shows that many learning outcomes can be enhanced by the presence of a wireless environment, and that students and instructors have positive feelings toward it (Varvel \& Thurston, 2002).

Surveys show that the use of student-owned laptops has increased dramatically on university campuses, with 82\% of students reporting laptop ownership in 2007-2008 compared to 68\% in 2005-2006 (McGill University Guidelines for Student Owned Laptops, 2009). Another recent study reported as many as $64.3 \%$ of students using their laptops in class (Fried, 2008). The advantages of using laptops during university classes include the following:

- $\quad$ Students can take notes faster, search for class-related materials, take online quizzes (Fang, 2009; Young, 2006), access course websites, read lecture summaries and related information (Barak, Lipson, \& Lerman, 2006), and print, integrate, organize, and maintain notes easier (Skolnik \& Puzo, 2008; University of Guelph Learning Services, 2010).

- $\quad$ Laptop use may engage students' minds and support performance (Aziz et al., 2010; Barak et al., 2006), increase students' motivation and collaboration, strengthen connections between disciplines, improve students' problem solving skills, help them learn to better manage their time and maintain a balanced lifestyle (Tan \& Morris, 2005), help them to better understand materials (Aziz et al., 2010), promote academic achievements (Barak et al., 2006; Kiaer, Mutchler, \&Froyd, 1998; Mackinnon \& Vibert, 2002; Siegle \& Foster, 2001; Stevenson, 1999), and enhance outdoor learning (Barak et al., 2006).

- $\quad$ Laptop use in class may provide students with an easy and convenient hands-on computing experience, increase students' spreadsheet skills (Skolnik \& Puzo, 2008; Tan \& Morris, 2005), enable immediate implementation of new programming concepts or procedures taught in class, and provide students with immediate feedback (Barak et al., 2006).

Several survey results show that students have expressed strong preferences for bringing laptops into the classroom and that they have highly positive opinions about the use of wireless laptops (Barak et al., 2006). Students feel that they should have the choice to bring laptops to class (Fang, 2009), especially when they believe they have been raised in the era of multitasking and can balance Internet use and classroom participation (Young, 2006). Students perceive laptops as being useful in preparing their homework, and also as being helpful in class, and in meetings with instructors (Barak et al., 2006).

However, studies show that students engage in substantial multitasking behavior with their laptops (Kraushaar \&Novak, 2010; Barak et al., 2006; Fried, 2008). For example, Kraushaar \& Novak (2010) reported that students have non course-related software applications open and active approximately $42 \%$ of the time. Moreover, Skolnik and Puzo (2008) reported that over half of the students surveyed acknowledged using laptops to engage in activities not related to the course, while class observations show that on average, approximately $15 \%$ of students are off-task at any one point in time. Another study reported that only $12 \%$ of students used their laptops for nondirected (non-learning) purposes, such as surfing the Web or sending e-mail messages (Barak et al., 2006). In yet another study, students reported that they multitasked (i.e., did things other than take lecture notes) for an average of 17 minutes out of each 75 minute class period (Fried, 2008). The "other" activities they engaged in included checking e-mail, instant messaging, browsing the Internet, and playing games (Fried, 2008). 
Students' academic performances are negatively affected by distractive multitasking (Kraushaar and Novak, 2010). Although students understate the frequency of e-mail and instant messaging used in the classroom when self-reporting on their laptop usage (Kraushaar \& Novak, 2010), studies show that the more students used laptops in class, the lower their class performance in general (Fried, 2008). Specifically, on average, students who use laptops during class take more time to perform tasks such as reading a typical academic passage (Bowman et. al., 2010; Kirschner \& Karpinski, 2010), pay less attention during lectures (Fried, 2008), make more mistakes while processing information than those who are sequentially or serially processing that same information (Kirschner \& Karpinski, 2010), find the material less clear (Fried, 2008), and are able to understand it less (Fried, 2008). Facebook users who use laptops simultaneously with other study activities have a lower self-reported GPA and spend fewer hours per week studying than do nonusers (Kirschner \& Karpinski, 2010). In addition, the "introduction of laptops in the classrooms coincides with the national decline in bar passage rates" (Trujillo, 2007; cited by Yamamoto, 2007). Moreover, results of a study in which students had the opportunity to report anything in the class or in the behavior of their fellow students that distracted them or prevented them from paying attention indicated that laptop use by fellow students was the single most reported distraction, accounting for $64 \%$ of all responses (Fried, 2008).

Indeed, among the reported disadvantages of using laptops in class include the following:

- $\quad$ Laptops can become a source of distraction if used for non-learning purposes (Barak et al., 2006; Skolnik \& Puzo, 2008; University of Guelph Learning Services, 2010; Young, 2006). They occasionally make sounds if students have forgotten to turn off the volume (Fang, 2009) and may promote non-class related usage and limit, or even reverse, benefits when measured in terms of academic performance (Grace-Martin \& Gay, 2001; University of Guelph Learning Services, 2010).

- $\quad$ Laptop screens can become walls between students and professors (Fang, 2009; Young, 2006) and inhibit classroom discussion (Yamamoto, 2007).

- $\quad$ Laptops can increase the possibility of academic dishonesty (Skolnik \& Puzo, 2008).

- $\quad$ Laptops can be heavy and difficult to carry throughout the day. Students must remember to keep the battery charged if no access to an outlet in the classroom is available. Laptops can be difficult to use in some classrooms, especially those with small flip-up desktops. If a laptop breaks down and the student has not printed out or backed up one's notes elsewhere, they may be lost for good. If a student takes notes from textbooks by hand, he must print lecture notes to integrate them with his text notes (University of Guelph Learning Services, 2010).

Because some felt that the disadvantages outweighed the advantages, several methods were proposed for dealing with laptop use in university classes. Integrative methods included the following: using filtering applications such as Respondus LockDown Browser to help faculty when they wanted students to bring their laptops to class to take online exams (Fang, 2009); disabling Internet and e-mail access but allowing laptops to reach campus web pages (Fang, 2009; Young, 2006); establishing rules with students who use laptops that they will sit on the front row so that the professor can occasionally glance at their activity (Fang, 2009); alternating between lectures and online quizzes; and involving students with some exploratory learning (Fang, 2009).

Restrictive methods have included banning laptop use and disabling the wireless network. Because of laptops' potential for temptation (Young, 2006), some pioneers in laptop programs (i.e., the Liverpool Central District of New York) have ended their programs after hearing teacher complaints of student abuse and the distractions caused by laptops in class (Fang, 2009). Many instructors have also chosen to ban the use of laptops in their classes (see Yamamoto, 2007 for a description of his experience and scientific evidence supporting this decision). In the event that the wireless network has been disabled, students can still use their laptops in the classroom, but only for taking notes and not much else. Any learning opportunities that would be possible with wireless access are therefore eliminated (Fang, 2009; Young, 2006).

Problems with restrictive methods include: cutting technology for professors who frequently rely on it; causing student discomfort by prohibiting the digital devices to which they are accustomed; creating a negative image (i.e., professor vs. technology) of a professor and hurting student-teacher relations; and sending the message that students are not trusted to take responsibility for their learning (Fang, 2009). 


\section{PRIMARY DATA COLLECTION}

Searches were conducted to find out the following: (1) the number of Canadian universities that have wireless networks and the number of locations within a given university where students can access the Internet in class; (2) the number of universities that require laptops of students, the programs that require them, and whether the university actually states that a laptop is not necessary; (3) any current policies concerning laptop usage in class and what, exactly, they stipulated.

\section{Methodology}

We searched for "Canadian Universities" and relied on a list provided by Wikipedia. We then searched for each university, accessed the main website of each one and, on the main page, searched for key words such as "wireless", "laptop", "mandatory laptop", "laptop required", "bring a laptop", "laptop usage policies", "library", "computer services", "class policies", "course outline" and combinations of these keywords. We also searched for "laptop" in the university's most recent Academic Calendars (undergraduate and graduate) or students' handbooks and in the Frequently Asked Questions section. The universities were not contacted to obtain additional materials. The analysis was based solely on information found on the Internet. All universities providing information only in French, even when search terms were entered in English, were excluded from the analysis. (This was the case with most of the universities in Quebec). Athabasca University (online only) and First Nations University of Canada and St. Stephen's University, which did not have a search option on the main page, were also excluded from the analysis. A total of 68 universities remained.

\section{Results}

\section{Wireless Network}

Almost all of the universities we researched have wireless networks that cover, if not the entire campus, at least several buildings. However, the Atlantic School of Theology specifies on its website that wireless use is for academic purposes only and can only be obtained after signing an agreement regarding its use. Access to Western Wireless at the University of Western Ontario is only available to students, faculty, staff and visitors of the University who have a valid Western Electronic Identity. Based on the information we could gather online, it seems that out of 68 universities, only 2 universities do not have a wireless network. These 2 universities are the Lakehead University and the Royal Military College of Canada. As stated by their president, the Lakehead University does not have a wireless network environment due to health concerns ${ }^{1}$. No online information about a wireless network was found on the Royal Military College of Canada. Therefore, our results show overwhelming wireless coverage across Canadian universities and wide Internet access for students who bring their laptops to class.

\section{Requirement For Owning A Laptop}

Results showed that only 3 out of 68 universities require all of their students to have a laptop. These include Quest University, Acadia University and the University of Ontario Institute of Technology. However, 27 universities have particular programs that require laptops of students. Examples include: business (University of Alberta), graduate studies in business (Royal Roads University, Simon Fraser University, Queen's University, Ryerson University, University of Toronto, and York University), architecture, design and visual art programs (Grant MacEwan University, Capilano University, Kwantlen Polytechnic University, Vancouver Island University, University of Manitoba, Memorial University of Newfoundland, Saint Francis Xavier University, Carleton University, University of Guelph, OCAD University, and University of Waterloo), dentistry (Dalhousie University and University of Manitoba), science (University of Manitoba, Algoma University, and Royal Military College of Canada), education (Nipissing University), communication studies (York University), and engineering (University of Saskatchewan).

Some universities or programs strongly recommend having a laptop (University of Calgary, Fairleigh Dickinson University), merely recommend (Mount Royal University), encourage (University of the Fraser Valley, Vancouver Island University), assume frequent use (McMaster University) or state that having a laptop may 
facilitate students' studies at the university (Concordia University). Nevertheless, most of the universities (38 out of 68) do not require students to have a laptop in any of their programs, and some of them explicitly state that. Examples include Saint Mary's University, the University of Western Ontario, Concordia University and McGill University (i.e., "NO program other than the Richard Ivey School of Business at the University of Western Ontario requires a student to own a laptop"). The only identified policy available online regarding the introduction of mandatory laptops in specific academic programs was provided by Ryerson University ${ }^{2}$.

\section{Policies Concerning Laptop Use In Class}

We were unable to find any kind of policy regarding laptop use in class for 25 universities, even in course outlines available online. At a few universities, we were only able to find very little information regarding laptop use in class. For example, at Mount Royal University, the only information was a general statement encouraging instructors to discuss with colleagues what is considered to be acceptable and unacceptable technologies in class and to communicate their thoughts to students clearly. Similarly, an article in the students' newspaper, titled "Laptops a distraction to students - Professors at St. Francis Xavier look to ban laptops from classrooms," was the only relevant information found at Grant MacEwan University. A series of "laptops in the classroom" articles was found at Carleton University, together with stipulations on laptop use appearing in course outlines and others made by examination services.

Moreover, for most of the universities (34), the only policies regarding laptop use in class or during examinations were found in individual course outlines and therefore differ widely among instructors. Policies allowing the use of laptops for note-taking were found in course outlines at 23 different universities. Although the messages could be as simple as "If you use a laptop please refrain from writing emails, internet chatting, web surfing, etc" (from a course outline at the Memorial University of Newfoundland), most of the policies stated in course outlines also included a description of the rule or punishment for students who do not obey the rule. The following are examples of this:

- $\quad$ Students will be asked to sit in rows at the rear of the classroom (University of British Columbia, University of Waterloo, and University of Regina)

- $\quad$ Students will be asked to shut down their computers (University Canada West and the University of Western Ontario) or to stop using their laptops during class (Saint Francis Xavier University)

- $\quad$ Laptops will be confiscated until the end of classtime (University of Calgary)

- $\quad$ Students will be asked to leave the classroom (University Canada West, University of Northern British Columbia, Ryerson University and University of Western Ontario)

- A student's laptop will be banned until the end of the semester (University of Calgary, University of Alberta, McMaster University, Ryerson University, Trent University and University of Regina)

- $\quad$ All laptops will be banned until the end of the semester (University of British Columbia, University of Manitoba, Saint Francis Xavier University and University of Ottawa)

- $\quad$ Points will be deducted from a student's contribution score (Carleton University, University of Guelph and Nipissing University) or final grade (Ryerson University and University of Western Ontario)

- $\quad$ Punishments will be left at the instructor's discretion (University of Western Ontario)

Instructors at several universities have chosen to completely forbid laptop use in class. Examples include instructors at the University of the Fraser Valley, Vancouver Island University, Saint Francis Xavier University, Carleton University, University of Guelph, McMaster University, Queen's University, Ryerson University, Trent University, and Concordia University. Some instructors allow laptop use in class only with prior permission from the professor (i.e., Royal Military College of Canada, Bishop's University). Some instructors specify that they do not permit laptops during exams (i.e., University of Winnipeg, Acadia University, Saint Mary's University, Royal Military College of Canada, University of Prince Edward Island).

Some instructors require or encourage students to bring their laptops to class (i.e., Simon Fraser University, University of Guelph, University of Western Ontario, York University, University of Ontario Institute of Technology, University of Toronto). Moreover, several course outlines in the Law School at Dalhousie University 
specify that the examinations are administered using Exam4 software and that a few laptops are available for students who do not have one. In addition, students who wish to handwrite their exams can do so, but they must notify the Associate Dean's office. The Faculty of Law at Queen's University computer exams project allows students to request a computer exam and to use Soft to take examinations securely. These are downloaded to their own laptops by blocking access to files, programs and the Internet during an exam. Similarly, in one class at the University of Northern British Columbia and another one at Carleton University, the examinations are open book and students are allowed to bring laptops with them. McGill University is also investigating using laptops during exams in the Faculty of Law. There was agreement that students liked to use laptops for exams because they are more accustomed to typing than writing. This approach was not found to be scalable.

Several universities have specifications regarding laptop use in class in their university calendars or examination services. For example, it is stated that laptops or other electronic devices may not be used during examinations without prior approval of the Instructor (University of Lethbridge, University of Northern British Columbia, Nipissing University, and University of Toronto). It is also stated that students may use personal laptops only for taking notes and that their use for unrelated purposes might lead to students being asked to shut down their laptops or to leave class (University Canada West). The University of Toronto Academic Handbook states that the inappropriate use of laptops should be discouraged, while Waterloo University states under their online "Notebook Connection" section that if students decide to use their laptop during lectures, labs or tutorials, they should be considerate and make certain that their laptop usage does not interfere with the class.

The Faculty of Law at the University of Toronto has policies regarding laptops in class that stipulate that professors might limit or prohibit their use in class. The department of psychology at Saint Francis Xavier University has a similar policy stating that students who wish to use a laptop during class must seek permission from the instructor in advance, while inappropriate usage of laptops in the classroom will result in laptop privileges being revoked. The joint committee at the University of Windsor has considered the issue of the increase in laptop use in the classroom and concluded that a policy regulating their use is unnecessary, due to the existence of mechanisms that can be used to this end. The committee determined that the duty of all instructors was to ensure proper classroom management and to establish appropriate conditions for optimal student learning.

Ryerson University has a Learning EDGE Code of Conduct that regulates laptop usage in class ${ }^{3}$. The stipulations, given to the students at the notebook pickup and orientation session, emphasize that students are in the class to learn and that they should not allow their notebooks to interfere with their class work. It also states that the use of chat software in the classroom is strongly discouraged and may be forbidden at the instructor's discretion. According to this document, instructors are generally entitled to impose rules of etiquette for notebook operation in the classroom, and students are required to obey those rules. Instructors may even request "lids down," with failure to do so possibly resulting in the ejection of the student from the classroom.

Finally, McGill University has University Guidelines for Student Owned Laptops ${ }^{4}$ and Guidelines for the Use of Mobile Computing and Communications Devices in Classes at McGill ${ }^{5}$. Based on extensive research, the guidelines stipulate that instructors have flexibility in establishing the level of use they will permit in class and that it is advisable to establish the permissible conditions early and explicitly. The three main existing options are as follows: (a) laptops are allowable under specified conditions; (b) they are allowed as long as they are not disruptive; and (c) they are not allowed at all. Considering that students are more likely to respect usage permissions if they are provided with a clear rationale, the guidelines also specify rationales for different levels of usage. The three broad categories of such rationales are (a) respect, (b) freedom from distraction, and (c) course design. Regarding noncompliance, instructors are encouraged to first talk with the student(s) involved and, in case of problematic behavior in class, to "discuss the issue with colleagues, the departmental or unit director, the Associate Dean of their Faculty, the Dean of Students, or a member of Teaching and Learning Services."

Several universities have policies regarding special needs students. For example, at the University of Toronto, although students are generally prohibited from using laptops to write regularly scheduled examinations, students with special needs who find it difficult to hand write an examination should make alternative arrangements through the Accessibility Services Division. 


\section{CONCLUSION}

Although almost all the Canadian universities considered in this review provide wireless access, most of them do not require students to own a laptop or to bring a laptop to class. However, because trends show that more students are bringing laptops to class, it would be advisable for written guidelines to be made available online for instructors and students regarding the appropriate usage of laptops in class to avoid disturbance and low class performance. Studies have shown unstructured laptop usage in lecture classes to be a disadvantage (Fried, 2008). Therefore, it would be important to discover which factors in courses and in classroom environments are favorable to laptop use and which factors of laptop use interfere with learning. According to these, universities may develop policies stating the conditions under which programs or departments may require laptop ownership and the process of assisting students in buying them. Universities may also develop policies concerning appropriate laptop use in class, specifying conditions for maximum learning and, as much as possible, restrictions on laptop usage that distracts and contributes to poor performance. Our review has shown that the total prohibition of laptop use in class is not unusual. Even so, we could not find any data showing how the banning of laptops in class might affect student enrolment. Future researchers should conduct surveys and focus groups, perhaps, among professors and students alike to identify the possible positive and negative effects of banning laptops from class.

\section{FOOT NOTES}

${ }^{1}$ http://communications.lakeheadu.ca/bulletin/?display=bulletin\&bid=679\#2125

2 http://www.ryerson.ca/senate/policies/pol146.pdf

3 http://www.ryerson.ca/itm/pdf/orientation.pdf

${ }_{5}^{4}$ http://www.mcgill.ca/files/secretariat/Student_owned_Laptops.pdf

5 http://www.mcgill.ca/files/tls/MC2_guidelines_FINAL_11June2010.doc

\section{AUTHOR INFORMATION}

Magdalena Cismaru received a Ph.D. in Business Administration from the University of Houston. She is currently an Associate Professor of Marketing at the University of Regina. Her research has been published widely in a variety of journals such as Journal of Advertising, Marketing Theory, Journal of Health Psychology, Social Marketing Quarterly, International Journal of Public Health, Trauma, Violence, and Abuse, and International Marketing Review. E-mail: Magdalena.Cismaru@uregina.ca

Romulus Cismaru received an M.S. in Engineering from the University of Houston. He is currently an Instructor in Technology and Management at the University of Regina. His research has been published in the International Journal of Nonprofit and Voluntary Sector Marketing, International Review on Public and Nonprofit Marketing and Social Marketing Quarterly. E-mail: Romulus.Cismaru@uregina.ca

\section{REFERENCES}

1. Aziz, T., Khan, M.B., \& Singh, R. (2010). Effects of Information Technology Usage on Student Learning: An Empirical Study in the United States. International Journal of Management, 27(2), 205-217.

2. Bagley, C.A., Bristow, B., Rhodes, P.S., \& Rubin, B. (2003). Review of the literature on mobile computing. Prepared for the University of St Thomas UTAC committee. Retrieved from http://www.stthomas.edu/irt/about/advisory/UTAC/UTAC\%20Mobile\%20Computin.doc

3. Barak, M., Lipson, A., \& Lerman, S. (2006). Wireless laptops as means for promoting active learning in large lecture halls. Journal of Research on Technology in Education, 38(3), 245-263.

4. Bowman, L.L., Levine, L.E., Waite, B.M., \& Gendron, M. (2010). Can students really multitask? An experimental study of instant messaging while reading. Computers \& Education, 54(4), 927-931.

5. Fang, B. (2009). From distraction to engagement: Wireless devices in the classroom. Educause Quarterly $32(4), 1-10$.

6. Fried, C.B. (2008). In-class laptop use and its effects on student learning. Computers and Education, 50(3), 906-914. Retrieved from http://portal.acm.org/citation.cfm?id=1342673 
7. Grace-Martin, M., \& Gay, G. (2001). Web browsing, mobile computing, and academic performance. Educational technology \& Society, 4(3), 95-107.

8. Hill, M.C., \& Epps, K.K. (2010). The impact of physical classroom environment on student satisfaction and student evaluation of teaching in the university environment. Academy of Educational Leadership Journal, 14(4), 65-79.

9. Jarmon, A.L. (2008). Multitasking helpful or harmful? Student Lawyer, 36(8). Retrieved from http://noonien.wordpress.com/2009/08/18/multitasking-helpful-or-harmful/

10. Kiaer, L., Mutchler, D., \& Froyd, J. (1998). Laptop computers in an integrated first-year curriculum. Communications of the ACM, 41(1), 45-49.

11. Kirschner, P.A., \& Karpinski, A.C. (2010). Facebook and academic performance. Computers and Human Behavior, 26(6), 1237-1245.

12. Kraushaar, J.M., \& Novak, D.C. (2010). Examining the affects of student multitasking with laptops during lecture. Journal of Information Systems Education, 21(2), 241-252.

13. Lovett, H.A. (2009). Students using laptops in class do worse on tests. Retrieved from http://www.findingdulcinea.com/news/education/2009/march/Students-Using-Laptops-in-Class-Do-Worseon-Tests.html

14. Mackinnon, G.R., \& Vibert, C. (2002). Judging the constructive impacts of communication technologies: A business education study. Education and Information Technologies, 7(2), 127-135.

15. McGill University Guidelines for Student-Owned Laptops (2009). Retrieved from http://www.mcgill.ca/files/secretariat/Student_owned_Laptops.pdf

16. McGill University Guidelines for the Use of Mobile Computing and Communication Devices in Classes (2010). Retrieved from http://www.mcgill.ca/files/tls/MC2_guidelines_FINAL_11June2010.doc

17. Morton, M. (2009). University of Waterloo, Centre for Teaching Excellence, Student laptop use in the classroom. Retrieved from http://cte-blog.uwaterloo.ca/?p=839

18. Rubinstein, J.S., Meyer, D.E., \& Evans, J.E. (2001). Executive control of cognitive processes in task switching. Journal of Experimental Psychology: Human Perception and Performance, 27(4), 763-797. Retrieved from http://www.apa.org/pubs/journals/releases/xhp274763.pdf

19. Siegle, D., \& Foster, T. (2001). Laptop computers and multimedia and presentation software: their effect on student achievements in anatomy and physiology. Journal of Research on Technology in Education, 34(1), 29-37.

20. Stevenson, K. R. (1999, April). Learning by laptop. "School Administrator," 56(4), 18-21.

21. Skolnik, R., \& Puzo, M. (2008). Utilization of laptop computers in the school of business classroom. Academy if Educational Leadership Journal, 12(2), 1-10.

22. Tan, C.L., \& Morries, J.S. (2005). Undergraduate college students, laptop computers, and lifelong learning. The Journal of General Education, 54(4), 316-338.

23. Trujillo, L.A. (2007). The relationship between law school and the bar exam: A look at the assessment and student success. University of Colorado Law Review, 78, 69. Retrieved October 30, 2010 from http://ssrn.com/abstract=976059

24. University of Guelph Learning Services (2010). You and your library. Retrieved from http://www.lib.uoguelph.ca/assistance/learning_services/handouts/learning from_lectures.cfm

25. University of Saskatchewan Information Technology Services. (2010). Self-Study. Retrieved from http://www.usask.ca/its/docs/about its/ITS\%20Self\%20Study\%20June\%207\%202010.pdf

26. Varvel, V.E., \& Thurston, C. (2002). Perceptions of a wireless network. Journal of Research on Technology in Education, 34(4), 487-501.

27. Yamamoto, K. (2007). Banning laptops in the classroom: Is it worth the hassles? Journal of Legal Education, 57(4), 1-44.

28. Young, J.R. (2006). The fight for classroom attention: Professor vs. laptop. The Chronicle of Higher Education. Retrieved from http://chronicle.com/article/The-Fight-for-Classroom/19431 